\title{
Traces of Indigenous Buff Pottery Industry of Shahr-I Sokhta; Using Semi-Quantitative Analysis of Elements XRF
}

\author{
H. SARHADI DADIYAN ${ }^{*}$, V. POURZARGHAN ${ }^{\mathrm{a}}, \mathrm{H}$. MORADI ${ }^{\mathrm{b}}$ and M. RAZANI \\ ${ }^{a}$ Department of Archaeology and Archaeological Research Center, University of Zabol, IRAN \\ ${ }^{b}$ Ph.D. student in Archaeology, University of Tehran, IRAN \\ ${ }^{c}$ Faculty of Conservation, Department Conservation-Restoration of Historic-Cultural Properties, Art \\ University of Isfahan, Isfahan, P.O.Box:1744, IRAN
}

\begin{abstract}
Shahr-i Sokhta is a historical settlement in south-eastern of Iran in the province of Sistan and Baluchestan, where the first settlement history goes back to $3200 \mathrm{BC}$. The results of excavations show four cultural-settlement period (I-IV) in this city that is divided into 11 phases. Period (II) goes back to 2500-2800 BC. The history of period (III) is equivalent to 2300-2500 BC, and history of period (IV) is suggested between 1750 and $1800 \mathrm{BC}$. This archaeological site is located $57 \mathrm{~km}$ from Zabol-Zahedan road. This site is registered as seventeenth heritage of Iran in UNESCO. One of the prominent features of this archaeological area is the existence of a lot of pottery shards on the surface of hills. Most of these pottery shards are buff color and have extensive domain from light buff to brick and greenish. Also, red and grey potteries have put in the next classification which the number of them is so little. Archaeological excavations carried out in this site pulled out thousands of pottery shards from the soil that are mostly buff-colored pastes. Also, among the pottery remnants of this 150 hectare site, clay pottery with red and gray paste have been seen. Archaeologists believe that most of the buff pottery shards are locally made. Hence, to determine whether this hypothesis is true, a scientific analysis was done to determine the chemical compositions of the pottery shards. In this paper, 15 pottery sample have been selected which all of them belong to settlement period II-III and goes back to 2200-2800 BC. The samples was tested using instrument analysis XRF to determine the major and trace elements of these potteries. The results analyzed using hierarchical cluster analysis (HCA) to specify pieces of pottery in two group local and nonnative. The results show that most of pottery is locating in a specific group with name of production group, where the samples no. 18259-9, 18265-10, 18266-13, 18273-4, 18271-15 are not locally made and located in another group. Based on the instrumental results, red and grey pottery are not related to Shahr-I Sokhta and probably these potteries are imported from another place.
\end{abstract}

Keywords: Shahr-i Sokhta, Buff Pottery, XRF, HCA, Local production, Import

* - Corresponding author: hossein.sarhaddi@gmail.com 


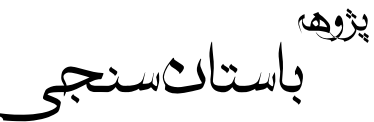

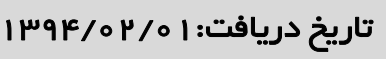

مقاله يزّوهشى

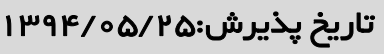

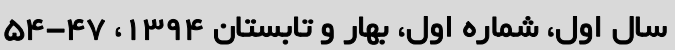

\section{تحليل مقدماتى از ردياى بومى بودن صنعت سفالهاى نخودى شهر

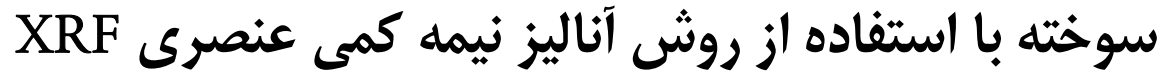

\section{حسين سرحدى داديان "، وحيد بور زرقان '، حسين مرادى '، مهدى رازانى"}
' . حسين سرحدى داديان عضو هيئت علمى باستانشناسى - مركز تحقيقات باستانشناسى دانشكاه زابل،ايران '.

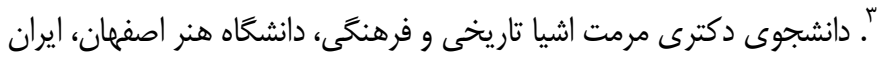

\section{جكيده}

شهر سوخته محوطهاى آغاز تاريخى است كه در جنوب شرق ايران در استان سيستان و بلوجستان واقع شده است و تاريخ آغاز استقرار

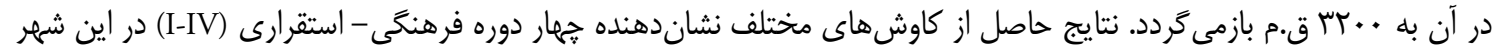

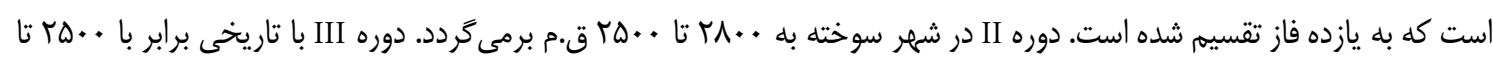

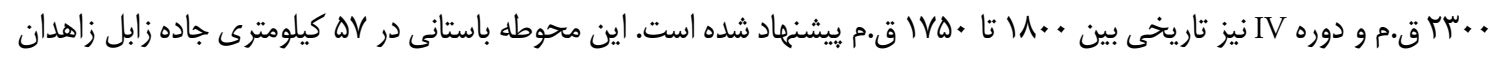

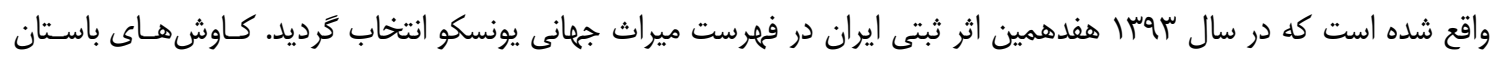

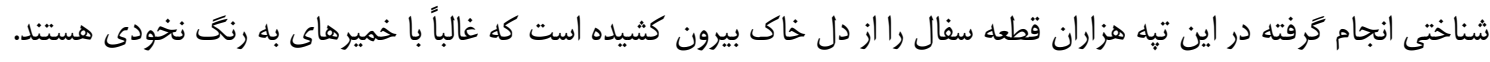

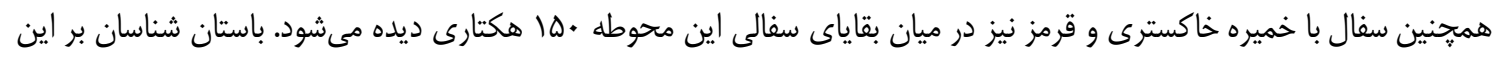

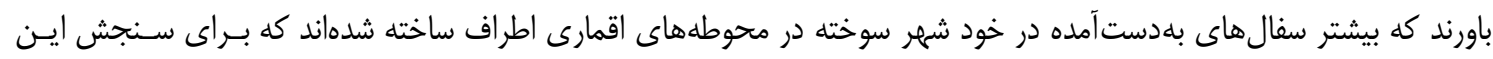

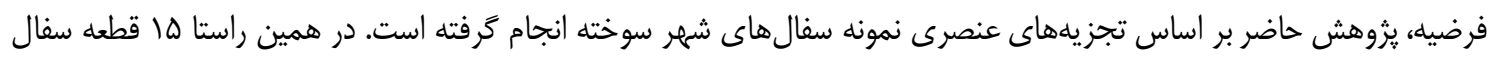

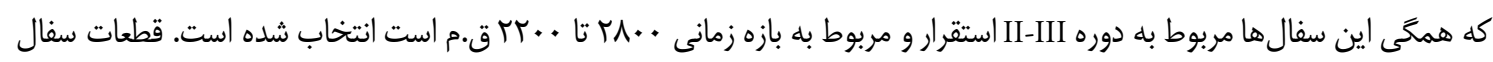

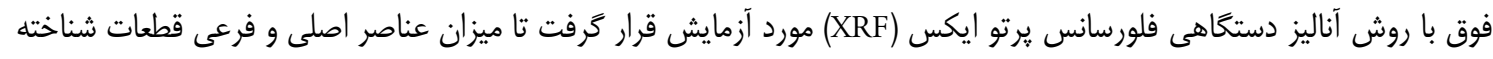

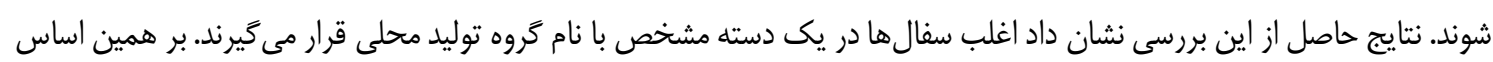

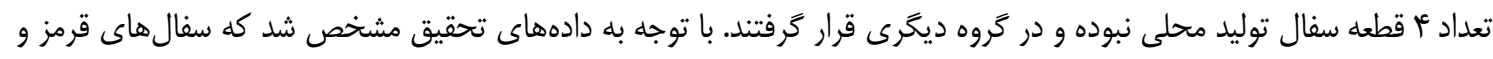

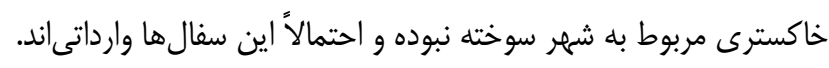

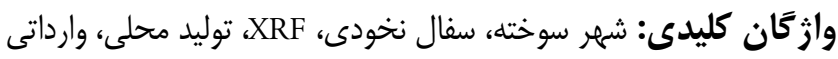

" نويسنده مسئول: سيستان و بلوحستان زابل كيلومتر دو جاده بنجار پرديس جديد دانشكاه زابل. كد يستى

بـ بـ الكترونيك: Hossein.Sarhaddi@gmail.com 
علت تغييرات احتمالى اقليمى مهمترين عامل طبيعى و

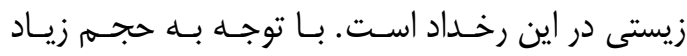
سفالهاى نخودى در اين محوطه نسبت به سفالهـاى رجاي

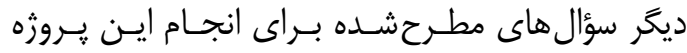

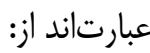
1- سفالهاى نخودى داراى خه تفاوتهايى از نظر

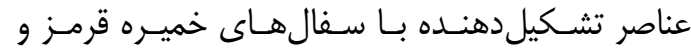

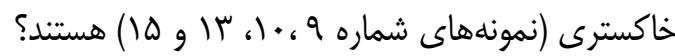
r- بر اساس نتايج آزمـايشهـا، تجزيـهـ و تحليـل عناصر تشكيل دهنده، آيا سفال هاى نخودى بومى هستند يا از نقاط ديكر به شهر سوخته واردشدهاند؟

\section{r- ب - روش تحقيق}

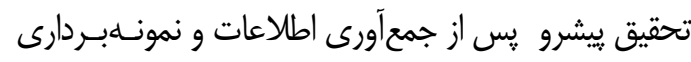

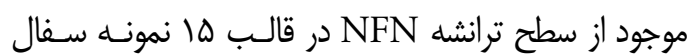

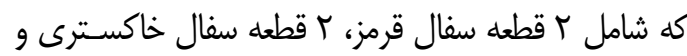
بقيه قطعات نخودى انتخاب شد. اين قطعات به سريرستى سيدمنصـور سيدسـجادى از بخـش مسـكونى در طـى إنى

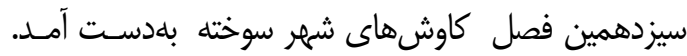

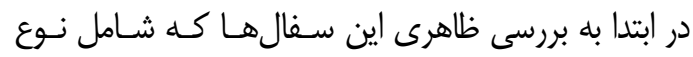

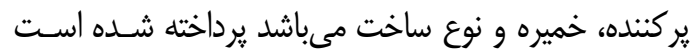

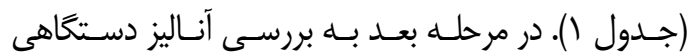

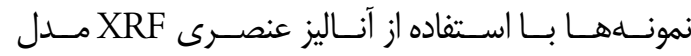
PW1480 فيلييس توسط شركت كانساران بينالود مشهمد

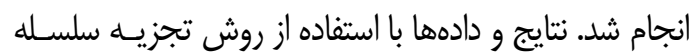

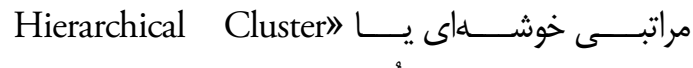
(HCA) 《Analysis درنهايت با توجه به نتايج حاصله از دادهها به بـومى بـودن سفالهاى نخودى يرداخته شده كه در بحث بــهـ آن اشـاره

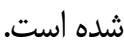

\section{ب- بيشينه تحقيق}

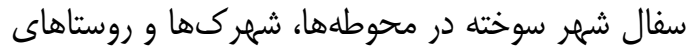

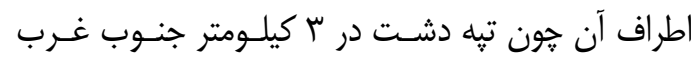

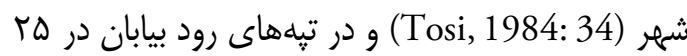

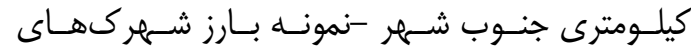

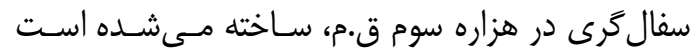

| - 1 - مقدمه

تبه شـهر سـوخته در حـوزه جنـوب شـرق ايـران، اسـتان

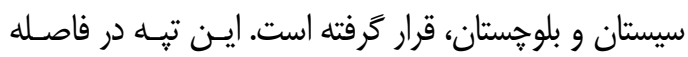

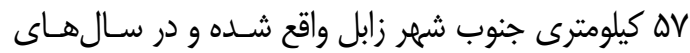

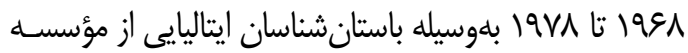

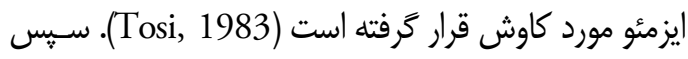

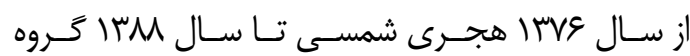

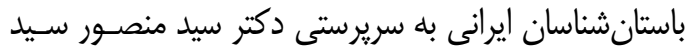
سجادى به كاوش در بخشهاى مختلف اين تيـه كليـدى

در جنوب شرق ايران مشغول بودند (Sajjadi, 2003). نتايج كاوشهاى مختلف نشـاندهنـــه جهـار دوره

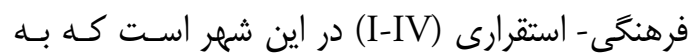

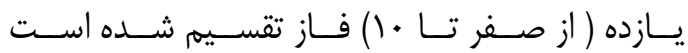

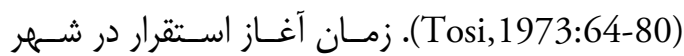

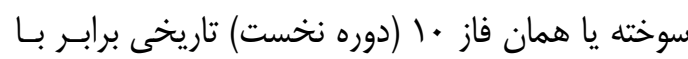

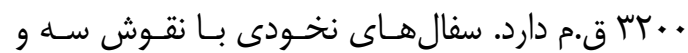

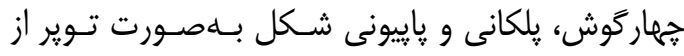

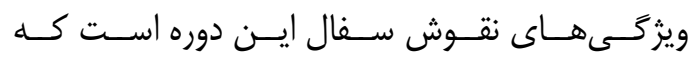

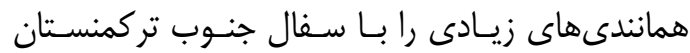

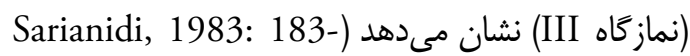
134

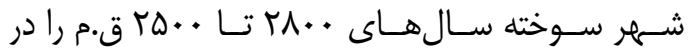

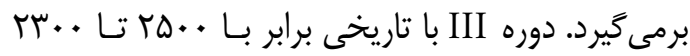

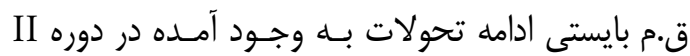

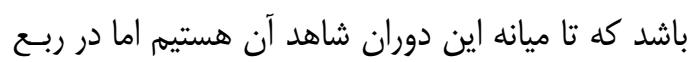

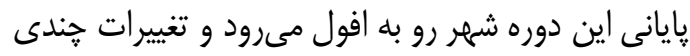

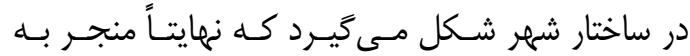
فروياشى شهر در يايان دوره IV (فـاز صـفر) مسىشـود.

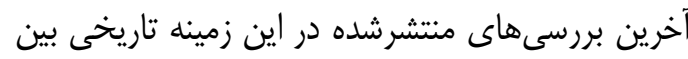

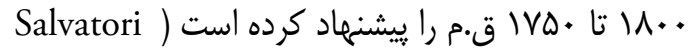

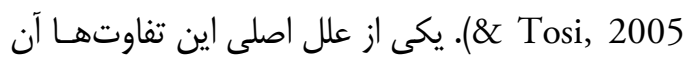

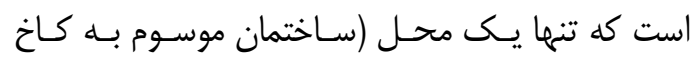
سوخته) منسوب به اين دوره حفارى شده است و بقاياى

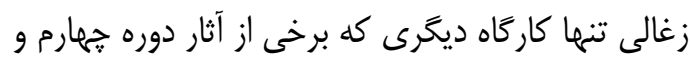

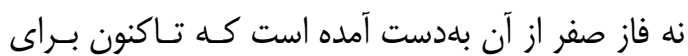

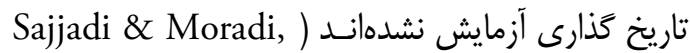
78 :2014). تغيير بستر درياحه هامون در اين دوران به إنه

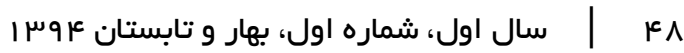


مختلف ازجمله نوع ير كنندها، نوع ساخت و نقوش انجام

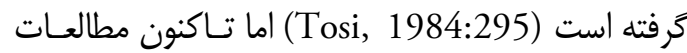
شيميايى بر روى سفال هاى شهر سوخته انجـام نكَرفتـه است. براى اين هدف در مجموع تعداد ها قطعه سفال از سطح ترانشه XFN از بخش مسكونى شرقى كه از دوره

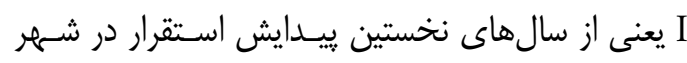
سوخته تا دوره جههارم مورد سكونت واقع شده است، بـاسـا

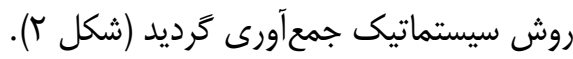

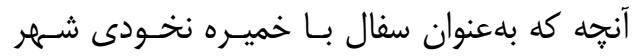

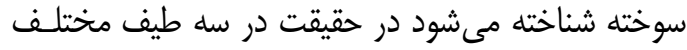

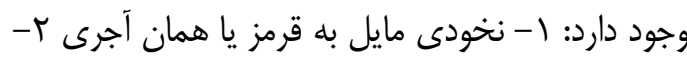
نخودى خالص و ّا- نخودى مايل بـه سـبز كـه بسـيار محدودتر از دو نمونه نخست مىباشد. ازآنجايى كه خميره

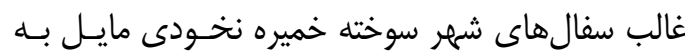

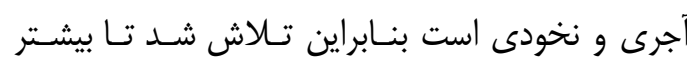
نمونههاى كردآورىشده از اين دست باشند تـا مـا را در رسيدن به نتايج مورد نظر بهتـر يـارى كنتــــ دو نمونسه

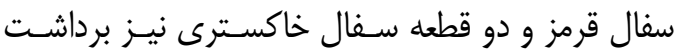
كرديد تا جامعه آمارى همه طيفهاى سفالى موجـود در

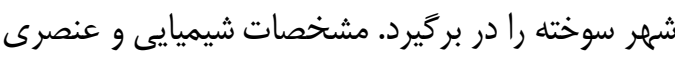

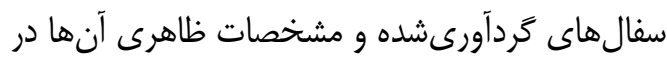

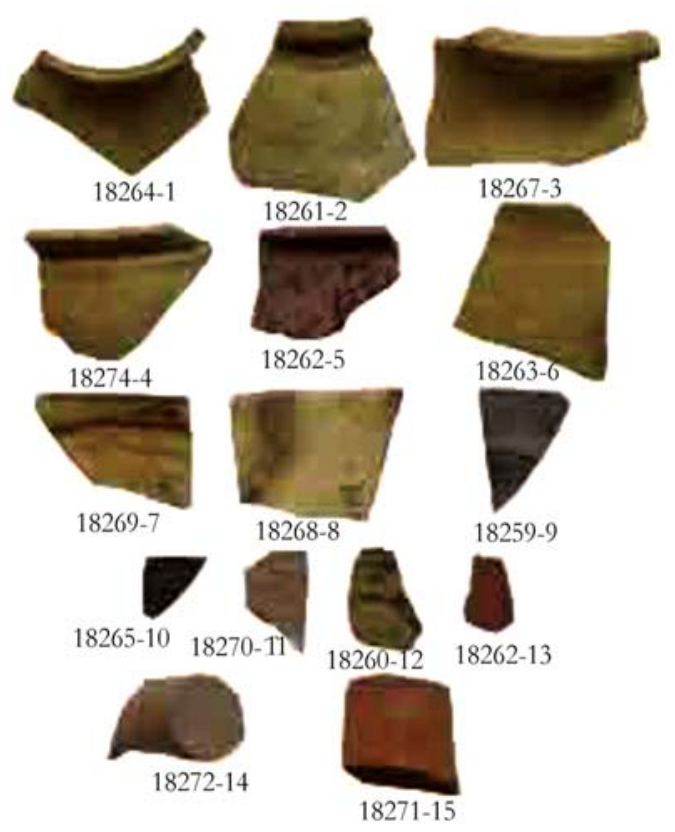

شكل r: تصوير سفالهاى گردآورىشده از سطح شهر سوخته براى آزمايش برد

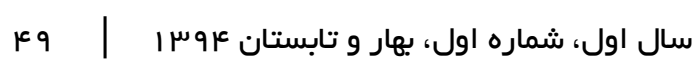

(شكل ا (Biscione, 1990: 394). كـه در دوره II و به كاركاههاى صنعتى تخصصى توليـد سـفال و بـا

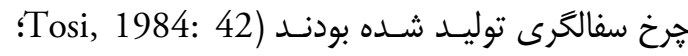
(Vidale \& Tosi, 1996: 252 سفال رايج در شهر سوخته است كه در طيف كسترداى :خهاى

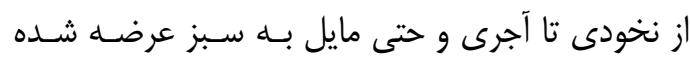

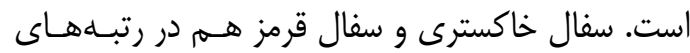

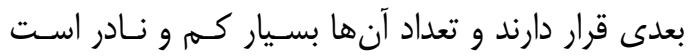

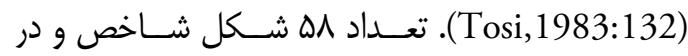
مجموع علا فرم بر اساس جدول شيارد در شهر سوخته شناسايى شده است (Tosi, 1983: 136 ؛ Salvatori (and Vidale, 1997: 42. fig 68 روى سطح شهر سوخته، برجستهترين ويزتى ظـاهرى

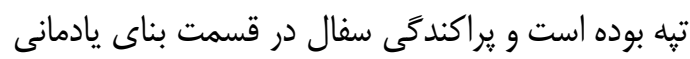

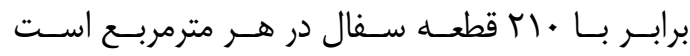

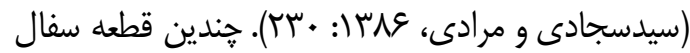
نيز از مناطق مختلف سيستان براى ياسخ بـهـ سـؤالاتى

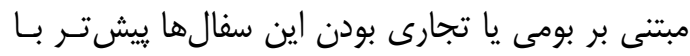

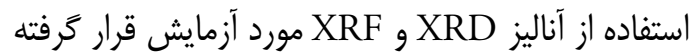

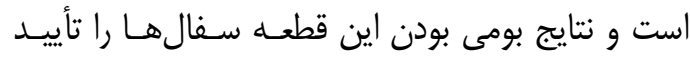
مى كند (Sarhadi dadyan et al., 2015:4).

$$
\begin{aligned}
& \text { r- مواد و روش تحقيق } \\
& \text { أ-1 - معرفى نمونهها }
\end{aligned}
$$
يزوهشهاى زيادى روى سفالهاى شهر سوخته در ابعاد

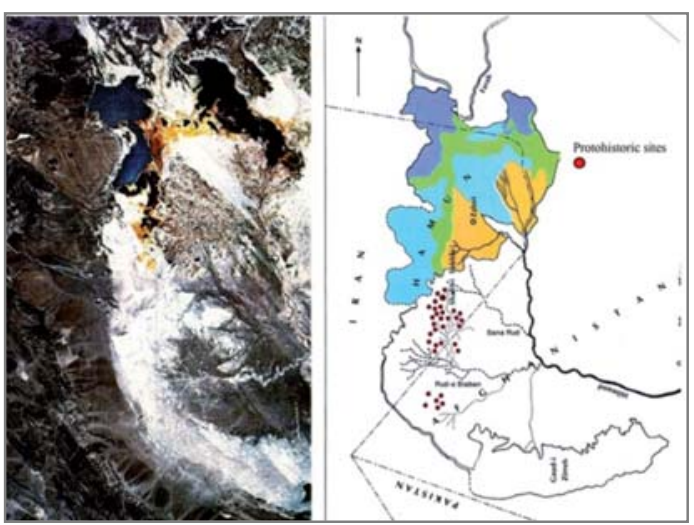

شكل (: ب) عكس ماهوارهاى از شهر سوخته الف) همراه تيههاى

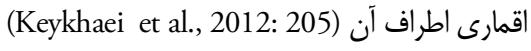


جدول (: مشاهدات ظاهرى سفال هاى گردآورىشده از شهر سوخته

\begin{tabular}{|c|c|c|c|c|c|c|c|c|}
\hline دوره & نوع خميره & ساخت & رنتى نقش & شاموت & رنغ بدنه & رنغ خميره & فرم & شماره \\
\hline II-III & استاندارد & هُخ & 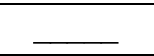 & ماسه بادى & نخودى & نخودى & خمره & MYGY - \\
\hline II-III & استاندارد & קخ קساز & قهوه اى تيره & ماسه بادى & نخودى & نخودى & خمره & $|A Y G|-T$ \\
\hline II-III & خشن & קخ קساز & - & شن ريز & نخودى & نخودى & خمره & MYSV -r \\
\hline II-III & استاندارد & קخ קخساز & قهوماى & ماسه بادى & نخودى & نخودى & خمره & $M T h^{\prime}-r^{c}$ \\
\hline II-III & خشن & קخ קساز & 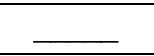 & شن ريز & آجرى & آجرى & خمره & MYGT -D \\
\hline II-III & استاندارد & 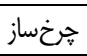 & $\bar{L}$ & شن ريز & نخودى & نخودى & خمره & MYGT-G \\
\hline II-III & استاندارد & קخ קساز & قهوماى & ماسه بادى. شن ريز & نخودى & نخودى & كاسه & $14 r 99-V$ \\
\hline II-III & استاندارد & هخخساز & قهوماى & ماسه بادى . & نخودى & نخودى & كاسه & 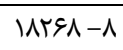 \\
\hline II-III & ظريف & קخ קساز & 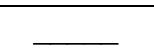 & ماسه بادى & خاكسترى & خاكسترى & كاسه & ARQQ -q \\
\hline II-III & ظريف & هُخ קسز & سياه & ماسه بادى & خاكسترى & خاكسترى & كاسه & MYYQD-1. \\
\hline II-III & استاندارد & هخ קساز & قهوهاى روشن & ماسه بادى & نخودى & نخودى & كاسه & $\mid A r V \cdot-11$ \\
\hline II-III & ظريف & קخ קساز & قهوماى تيره & شن ريز & نخودى & نخودى & ليوان & IATE. -IT \\
\hline II-III & ظريف & جخ קساز & 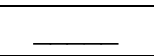 & ماسه بادى & قرمز & قرمز & كاسه & WNYGS-IT \\
\hline II-III & استاندارد & هرخ קساز & 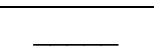 & ماسه بادى. شن ريز & نخودى & نخودى & ليوان & MATVT-IF \\
\hline II-III & استاندارد & קخ קساز & 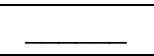 & ماسه بادى & قرمز & قرمز & خمره & IATVI-ID \\
\hline
\end{tabular}

در دماى ه • ا درجه سانتى گراد حرارت داده شـد و ايـن

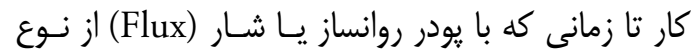

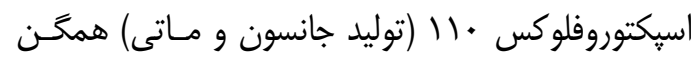

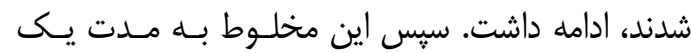

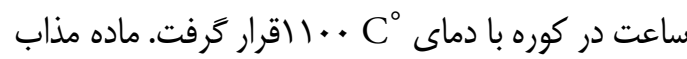
همگًن شده در يك ظرف قالبدهى شد و به تدريج به-

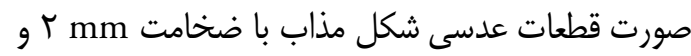

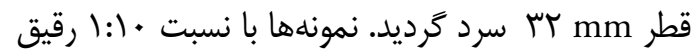

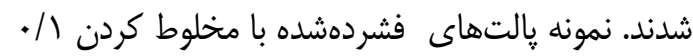

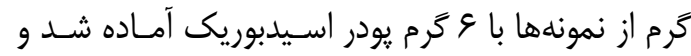

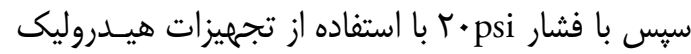

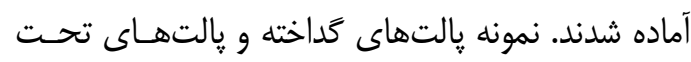

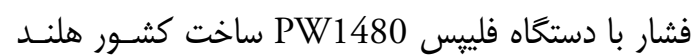
براى تجزيه و تحليل عناصر اصلى و كمياب در شـركت

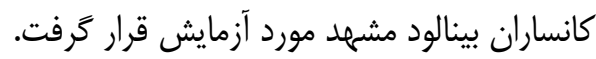

\section{ه- نتايج و بحث} مشخصات كلى عناصر تركيبى سفالهاى آزمايش شــده در جدول شماره Y و س در ادامه آورده شده است. نمودار

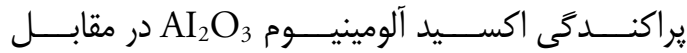
اكسيدكلسـيم CaO، اكسـيد منيـزيه
جدول ا آمده است. همخى سفال هاى برداشتشده رات

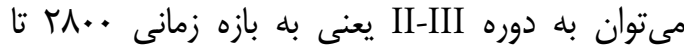

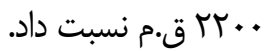

\section{r-r-r - مواد و روش تحقيق}

تجزيه شيميايى يكى از روشهــاى مطمـئن بـهـمنظـور

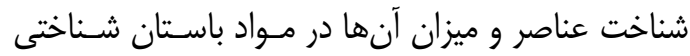
هieber ) همانند سفال، شيشه، اشيا فلزى و غيره است ونسان ؛Broekmans et al., 2008 set al., 1976 Wong et al., ؛Marghussian et al., 2009 ؛Ramli et al., 2011a, b, 2012 2010 Zuliskandar et al., 2011 اشعهى ايكس (XRF) روشى نيمه كمى است كـه بــه

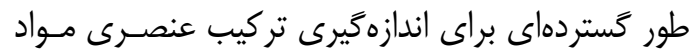

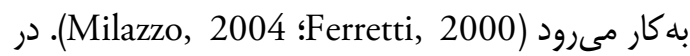
مطالعات متعددى براى بررسى سفالهـا، از روش XRF

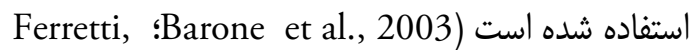
Leung and Lao, ؛Klein et al., 2004 2000 2000؛ Pillay et al., 2000 بـراى تجزيـه و تعيـين تركيب شيميايى هر يك از نمونهها سفالهاى مورد نظر

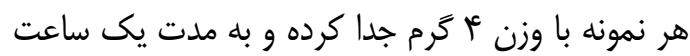


آن ها با خميره سفال بود. براى اين مهـهم بـا استفاده از

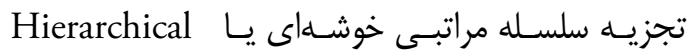

(HCA) Cluster Analysis

ألومينـا ${ }^{2} \mathrm{AI}_{2} \mathrm{O}_{3} \mathrm{~S}_{3}$

روبيديوم انجام گرفت (50) :5arhadi-Dadian, 2015).

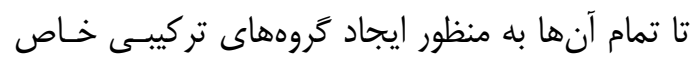

بلووسيله عناصر مهم از يكديخر متمايز شوند.
اكسـيد تيتـانيوم TiO و استرانسـيوم Sr در مقابـل

روبيديوم Rb بهمنظور نشان دادن تفاوت ميان تروهها با

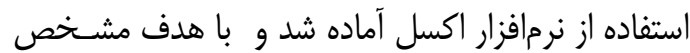

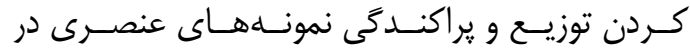

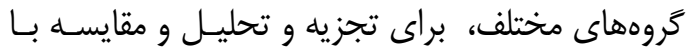

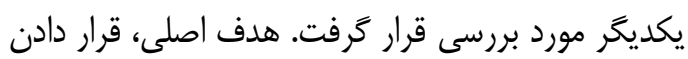
نمونهها در كروههاى در نظر گرَفته شده و نمايتاً مقايسه

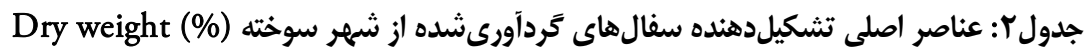

\begin{tabular}{cccccccccccc}
\hline Sample & $\mathrm{Si}$ & $\mathrm{Ti}$ & $\mathrm{Fe}$ & $\mathrm{Al}$ & $\mathrm{Mn}$ & $\mathrm{Ca}$ & $\mathrm{Mg}$ & $\mathrm{Na}$ & $\mathrm{K}$ & $\mathrm{P}_{2} \mathrm{O}_{5}$ & $\mathrm{SO}_{3}$ \\
$18259-9$ & 55.55 & 0.81 & 8.71 & 17.84 & 0.10 & 5.79 & 4.43 & 1.43 & 3.44 & 0.21 & 0.42 \\
$18260-12$ & 50.88 & 0.53 & 5.57 & 12.57 & 0.10 & 12.62 & 6.84 & 3.04 & 1.80 & 0.12 & 0.50 \\
$18261-2$ & 51.78 & 0.60 & 6.01 & 13.69 & 0.11 & 10.99 & 5.46 & 2.34 & 2.33 & 0.13 & 1.72 \\
$18262-5$ & 51.27 & 0.44 & 4.71 & 11.13 & 0.09 & 10.40 & 5.87 & 4.33 & 2.65 & 1.39 & 1.05 \\
$18263-6$ & 49.30 & 0.49 & 4.97 & 11.25 & 0.09 & 12.07 & 5.46 & 3.86 & 2.47 & 0.23 & 0.85 \\
$18264-1$ & 49.69 & 0.47 & 4.81 & 10.63 & 0.09 & 12.71 & 7.67 & 2.77 & 2.37 & 0.17 & 2.80 \\
$18265-10$ & 60.39 & 0.82 & 8.84 & 16.58 & 0.09 & 2.40 & 4.66 & 1.42 & 3.21 & 0.13 & 0.15 \\
$18266-13$ & 53.14 & 0.73 & 7.22 & 16.60 & 0.08 & 5.00 & 3.74 & 1.82 & 3.42 & 0.15 & 0.34 \\
$18267-3$ & 52.89 & 0.54 & 5.56 & 12.59 & 0.12 & 12.75 & 7.03 & 2.75 & 1.96 & 0.16 & 0.73 \\
$18268-8$ & 52.86 & 0.52 & 5.35 & 12.36 & 0.10 & 11.34 & 5.46 & 2.21 & 2.63 & 0.14 & 2.00 \\
$18269-7$ & 52.30 & 0.46 & 5.05 & 10.58 & 0.09 & 11.62 & 9.87 & 2.77 & 2.14 & 0.11 & 1.33 \\
$18270-11$ & 51.34 & 0.58 & 6.10 & 13.29 & 0.11 & 12.36 & 6.00 & 2.25 & 2.74 & 0.30 & 0.73 \\
$18271-15$ & 62.64 & 0.75 & 6.79 & 15.26 & 0.06 & 1.55 & 3.33 & 2.61 & 2.71 & 0.60 & 0.17 \\
$18272-14$ & 47.36 & 0.51 & 4.78 & 10.51 & 0.08 & 12.69 & 5.09 & 3.23 & 3.09 & 0.18 & 2.98 \\
$18273-4$ & 49.57 & 0.56 & 5.64 & 12.24 & 0.10 & 11.85 & 6.07 & 2.98 & 2.43 & 0.27 & 0.72 \\
\hline
\end{tabular}

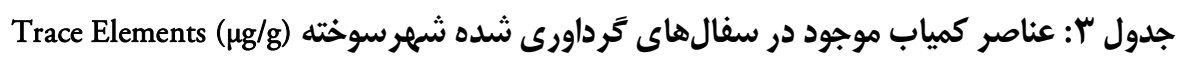

\begin{tabular}{ccccccccccccccccc}
\hline Sample & $\mathrm{Ba}$ & $\mathrm{Co}$ & $\mathrm{Cr}$ & $\mathrm{Cu}$ & $\mathrm{Nb}$ & $\mathrm{U}$ & $\mathrm{Th}$ & $\mathrm{Ni}$ & $\mathrm{Pb}$ & $\mathrm{Rb}$ & $\mathrm{Sr}$ & $\mathrm{V}$ & $\mathrm{Y}$ & $\mathrm{Zr}$ & $\mathrm{Zn}$ & $\mathrm{Cl}$ \\
$18259-9$ & 348 & 53 & 169 & 75 & 21 & 15 & 15 & 127 & 54 & 206 & 600 & 285 & 38 & 282 & 192 & 5414 \\
$18260-12$ & 399 & 25 & 171 & 86 & 9 & 17 & 8 & 144 & 42 & 85 & 1019 & 131 & 26 & 241 & 130 & 10815 \\
$18261-2$ & 438 & 43 & 155 & 86 & 18 & 6 & 18 & 132 & 79 & 114 & 677 & 157 & 28 & 229 & 131 & 9076 \\
$18262-5$ & 352 & 29 & 166 & 42 & 11 & 6 & 12 & 93 & 59 & 113 & 1161 & 106 & 25 & 205 & 131 & 26999 \\
$18263-6$ & 342 & 28 & 164 & 67 & 8 & 115 & 6 & 139 & 45 & 103 & 595 & 131 & 27 & 220 & 110 & 20208 \\
$18264-1$ & 359 & 31 & 152 & 43 & 3 & 12 & 10 & 118 & 44 & 94 & 967 & 108 & 22 & 202 & 106 & 10076 \\
$18265-10$ & 213 & 59 & 232 & 84 & 12 & 5 & 15 & 226 & 561 & 189 & 165 & 223 & 35 & 250 & 158 & 654 \\
$18266-13$ & 290 & 47 & 143 & 96 & 15 & 8 & 14 & 90 & 45 & 198 & 572 & 231 & 40 & 247 & 153 & 2809 \\
$18267-3$ & 355 & 42 & 146 & 50 & 9 & 9 & 17 & 120 & 100 & 92 & 1003 & 140 & 28 & 232 & 119 & 8641 \\
$18268-8$ & 344 & 21 & 168 & 68 & 8 & 16 & 4 & 108 & 54 & 107 & 926 & 138 & 26 & 241 & 107 & 5798 \\
$18269-7$ & 382 & 32 & 199 & 60 & 17 & 7 & 5 & 141 & 76 & 92 & 836 & 123 & 26 & 230 & 109 & 10976 \\
$18270-11$ & 439 & 28 & 163 & 63 & 15 & 10 & 13 & 166 & 44 & 110 & 652 & 148 & 27 & 225 & 123 & 8601 \\
$18271-15$ & 455 & 47 & 246 & 77 & 12 & 7 & 14 & 206 & 70 & 147 & 631 & 189 & 33 & 308 & 172 & 6352 \\
$18272-14$ & 384 & 16 & 120 & 108 & 6 & 7 & 7 & 112 & 41 & 101 & 610 & 119 & 27 & 237 & 115 & 16187 \\
$18273-4$ & 361 & 34 & 145 & 53 & 12 & 7 & 11 & 139 & 148 & 108 & 1628 & 154 & 29 & 215 & 142 & 13640 \\
\hline
\end{tabular}

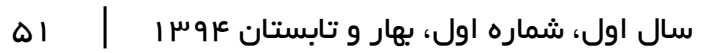


جدول شماره r محتواى عناصر اصلى سـفالهـاى

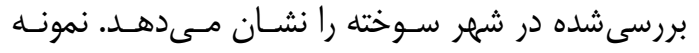

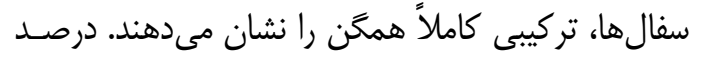
وزن خشك سيليكا

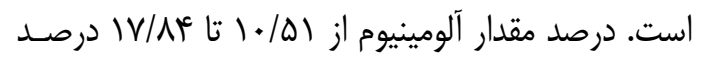

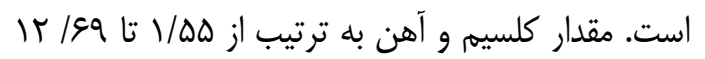

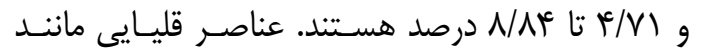

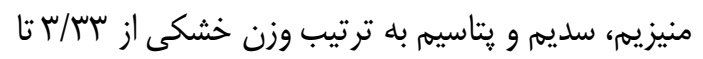

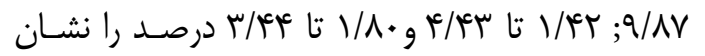

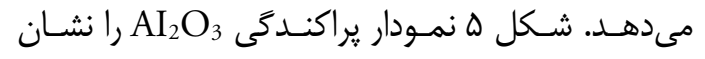

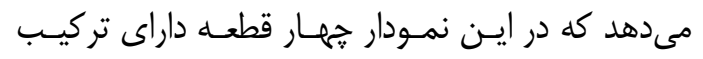
شيميايى مختلف در مقايسه با ساير نمونهها وجـود دارد كه در اين مقاله با شمارههاى

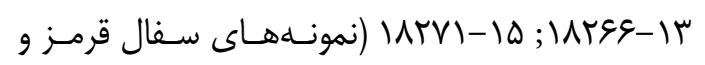
خاكسترى) مشخص شده است. اين جهار نمونه، مقدار بسيار زياد سيليكا، آلومينيوم، آهن و يتاسيهم و به همان نسبت درصد كمسى كلسيهم و نمئه

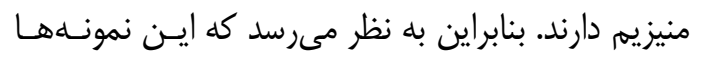

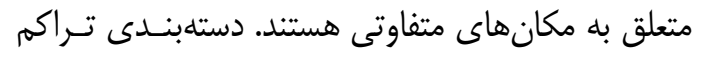

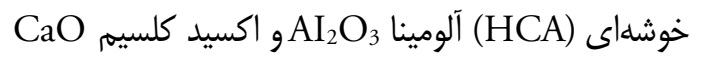

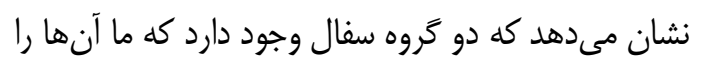
تحت عنوان گروههاى A, B مى شناسيه كه سفال هـاى

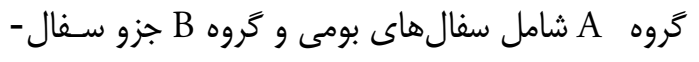

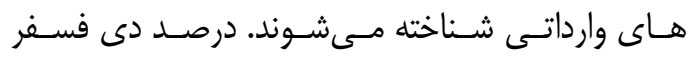
ينتاكسيد P

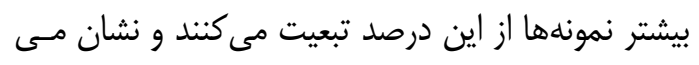

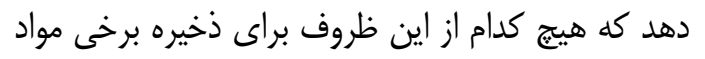
طبيعى و اركانيك مورد استفاده قرار نخر فتهاند.

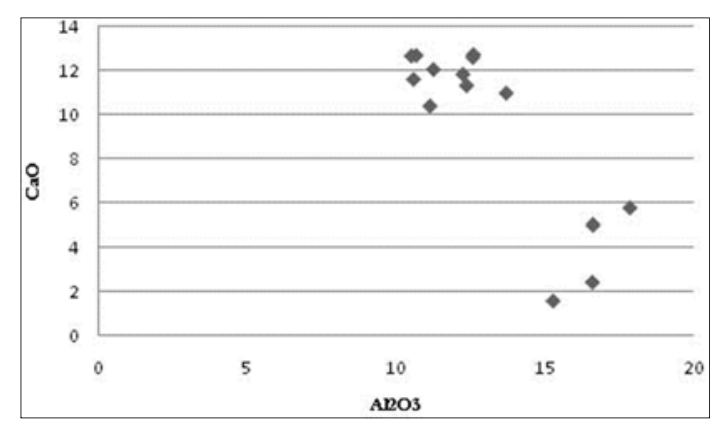

شكل ه: نمودار براكندىى اكسيد آلومينيوم در برابر اكسيد كلسيم

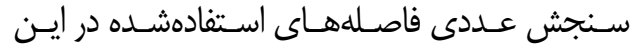

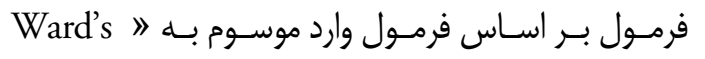
Linkage and Squared Euclidean Distance \&lgorithm انجام يذير شد. نتايج در نمـودار دنـــروكرام

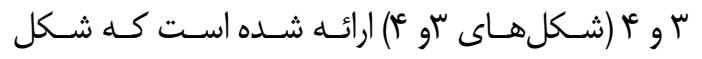

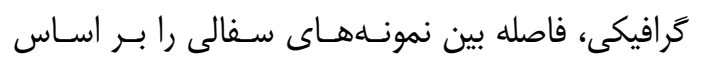

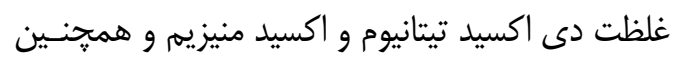

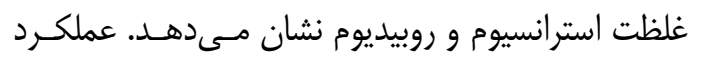

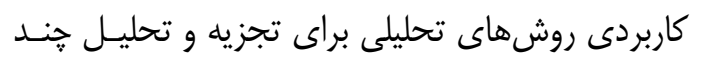

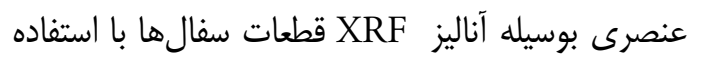

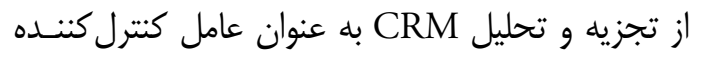
كيفيت در روند تجزيه و تحليل به كار برده شد.
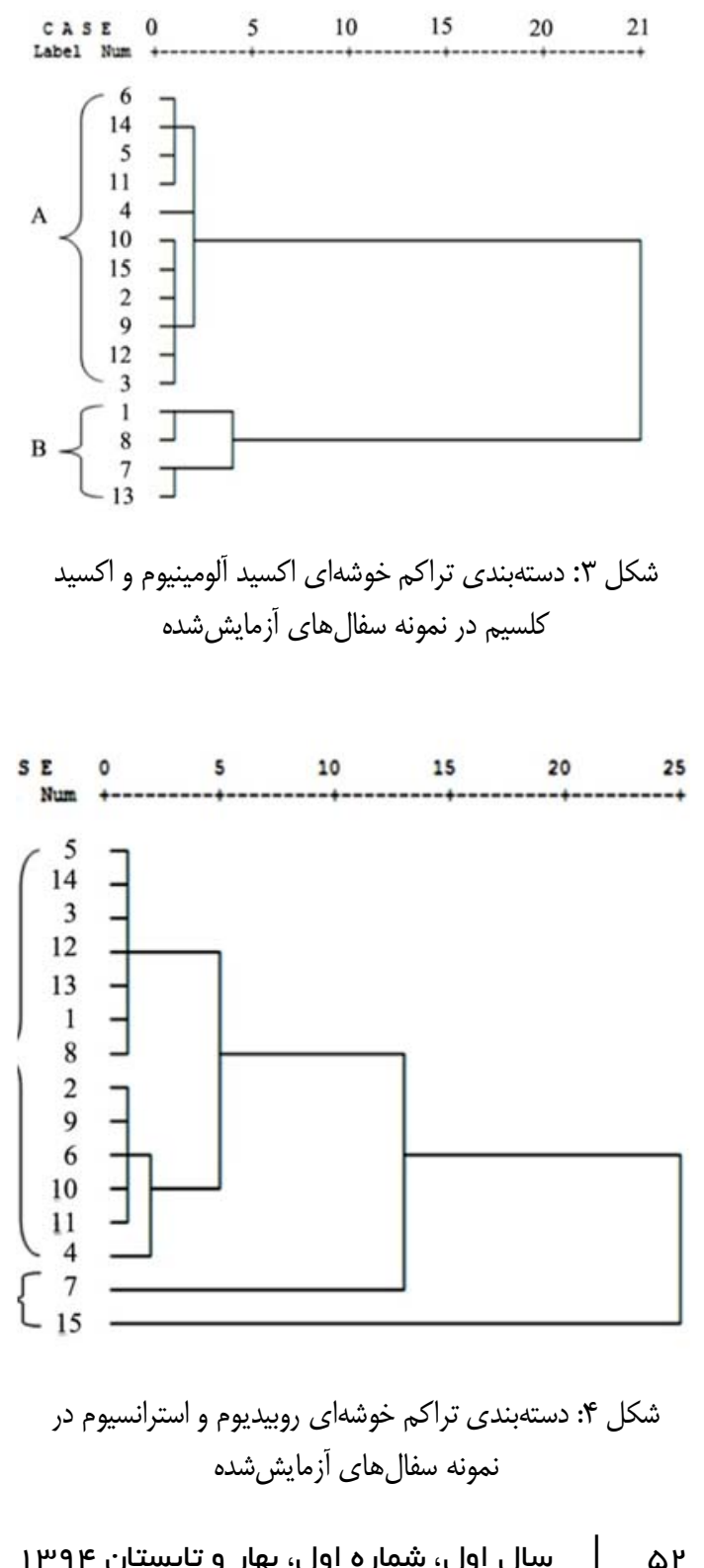

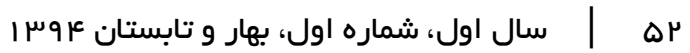




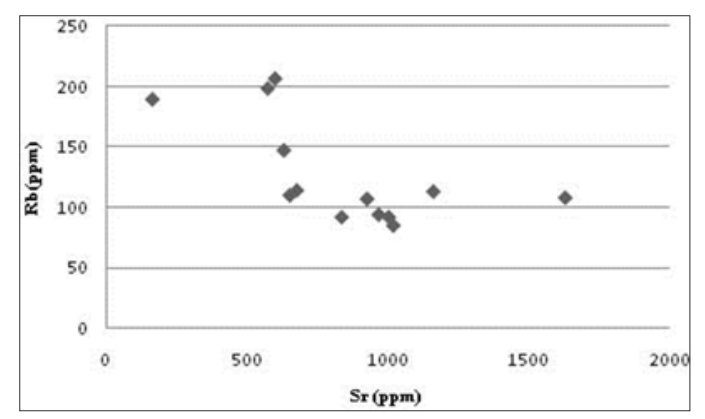

شكل צ: نمودار :راكندگى استرانسيوم در برابر روبيديوم

روبيديوم يك نتيجه متفاوت در مقايسه با دستهبنـدى

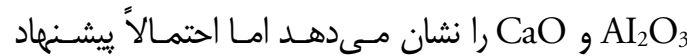

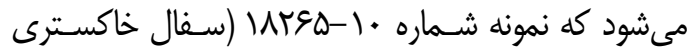

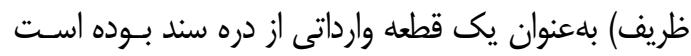

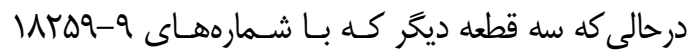

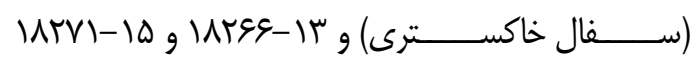
(سفال هاى قرمز) هستند توليد شهر سوخته نيستند.

\section{צ- نتيجه كيرى}

تجزيه عنصرى قطعات سفال شهر سوخته نشان مى دهد

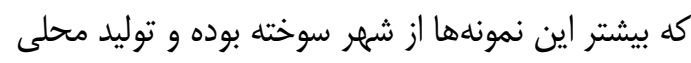

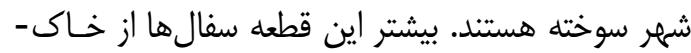

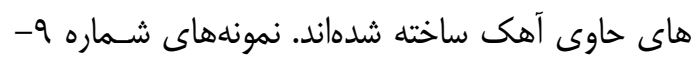

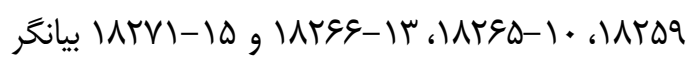

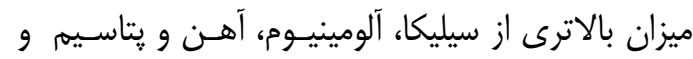
ميزان كمترى كلسيه، منيزيم است، بدين ترتيب مى بوان ييشنهاد نمود كه جهار نمونهى مذكور توليد شهر سوخته

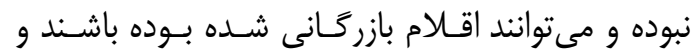

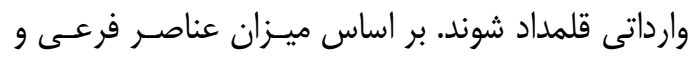

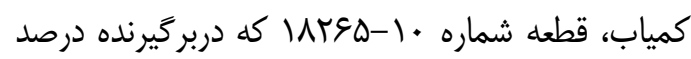
بالاترى سرب نسبت به ساير قطعهها بوده است مىتوان

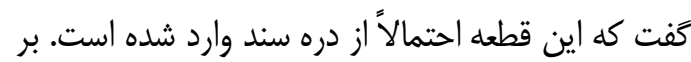

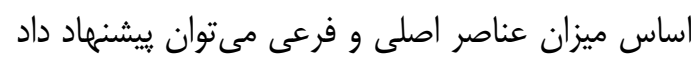
كه نمونdهـ ها نمىباشند. در واقع همانطور كه يِيش از اين توضيح داده شد سفال قرمز و خاكسترى بيشتر در منطقه بلوجستان و ونس

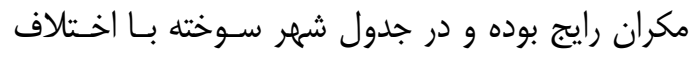

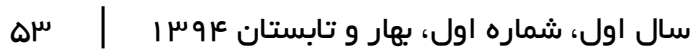

همجنين درصد بالاى اكسيدكلسيم CaO در يازده

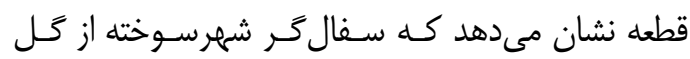
آهكى يا خاك حاوى آهك بلهعنوان منبع اصلى تهيه كَل سفال استفاده نموده است.

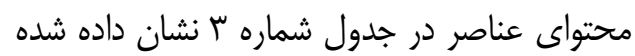

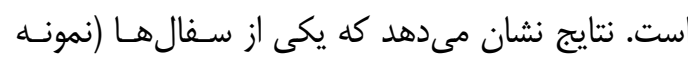

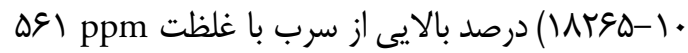

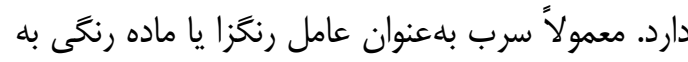
سفالهاى باستانى اضافه مـى شـده اسـت و در جوامـع باستانى از جمله دره سند سرب به عنوان عامل رنغَساز Colorant استفاده شده است (Caleb,1991). با ايسن حال بر اساس رنگ سفال هاى نخودى، به نظر مىرسـد

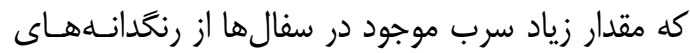
طبيعى بوده است كه بر روى سطح سفال وجود دارد. اين

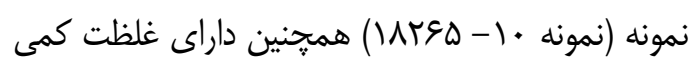
استرانسيوم نسبت به ساير نمونههاست. جهار نمونه كـه قبلاً ذكر شد بـا شـمارههـاى سا خاكسترى و قرمز، همجنين در مقايسه با ساير نمونههـا

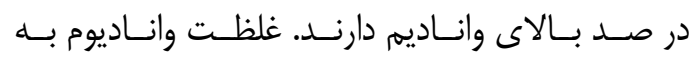

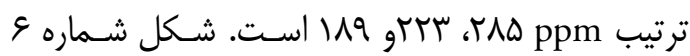
نمودار يراكندگى استرانسيوم در مقابل روبيديوم را نشان مىدهد كه بيانخر اين است كه بعضى قطعات توليد بومى لدى

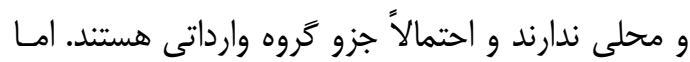

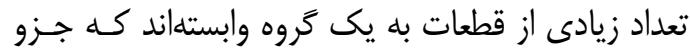

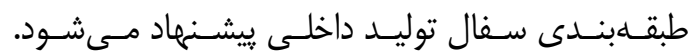

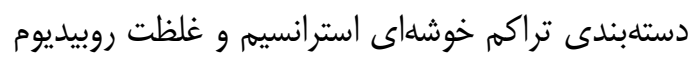

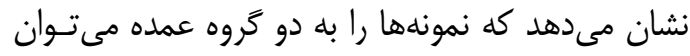
تقسيم كرد. بيشتر نمونهها در زروه A قرار دارند كـهـ در كروه توليدات محلى جاى مى گيرند ( Sarhadi-Dadian

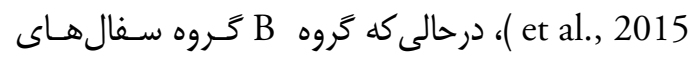
وارداتى است. دستهبندى تراكم خوشهاى استرانسـيوم و و غلظت روبيديوم نشان مى دهد كه دستهبندى نمونهای ما به دو گروه A و B صحيح است و در زروه A نمونسه سفالهاى توليد محلى و در گروه B سفال هاى احتمـالاً

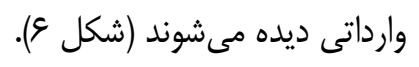

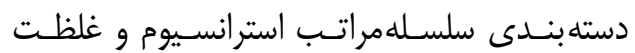




$$
\begin{aligned}
& \text { در اختيار قرار دادن نمونه سفالها تشكر نمايند. }
\end{aligned}
$$

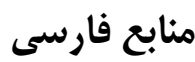

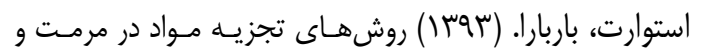

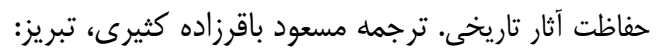

$$
\begin{aligned}
& \text { دانشخاه هنر اسلامى تبريز. }
\end{aligned}
$$

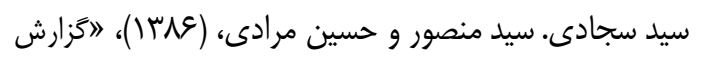

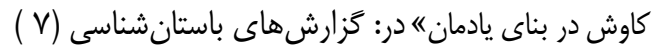

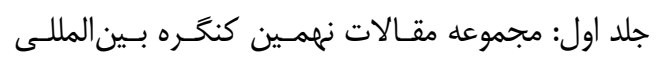

$$
\begin{aligned}
& \text { باستان شناسى ايران، جلد اول، يزوهشكده باستان شناسى }
\end{aligned}
$$

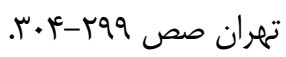

\section{منابع لاتين}

Piperno, M., \& Tosi, M. (1975). The Graveyard of Shahr-i Sokhta Iran.Archaeology, 186-197.

Ramli, Z., Nik Abdul Rahman, N., \& Samian, A. (2010-a). X-ray fluorescent analysis on Indo-Pacific glass beads from Sungai Mas archaeological sites, Kedah, Malaysia. Journal of Radioanalytical and Nuclear Chemistry, 287(3), 741-747.

Ramli, Z., Rahman, N. A., Shuhaimi, N. H., Jusoh, A., \& Hussein, M. (2012). Compositional analysis on ancient bricks from Candi Sungai Mas (Site 32/34), Bujang Valley, Kedah. American Journal of Applied Sciences, 9 (2), 196-201.

Ramli, Z., Rahman, N. H. A., Jusoh, A., \& Sauman, Y. (2011-b). X-Ray Diffraction and X-Ray Fluorescent Analyses of Prehistoric Pottery Shards from Ulu Kelantan. American Journal of Applied Sciences, 8(12), 1337.

Ramli, Z., Rahman, N. H. S. N. A., Samian, A. L., \& Yanno, M. A. (2011). Scientific analysis of ancient bricks at Bukit Pendiat temple (Site 17) and Pengkalan Bujang temple (Site 23). Research Journal of Applied Sciences, 6(7), 473-478.

Sajjadi, S. M. S., Foruzanfar, F., Shirazi, R., \& Baghestani, S. (2003). Excavations at Shahr-i Sokhta. First Preliminary Report on the Excavations of the Graveyard, 1997-2000. Iran, 21-97.

Sajjadi, S.M.S. and H. Moradi, (2014), Excavation at Buildings Nos. 1 and 20 at Shahr-i-Sokhta, International Journal of the Society of Iranian Archaeologists, Vol. 1, No.1, pp. 77-90

Sarhadi-Dadian, H. Ramli, Z. Nik Abdul Rahman, N \& Mehrafarin, R. (2015), X-Ray Differaction and X-Ray Flurescence Analysis of Pottery Shards from New Archaeological Survey in

$$
\begin{aligned}
& \text { بسيار زياد نسبت به سفال نخودى در ردههاى بعدى قرار }
\end{aligned}
$$

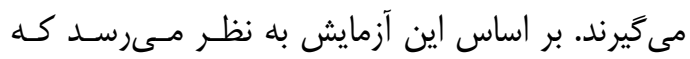

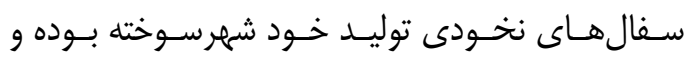

$$
\begin{aligned}
& \text { سفالهاى قرمز و خاكسترى از نقطهاى ديكًر بــهـ شهر تهر }
\end{aligned}
$$

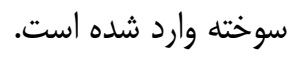

$$
\begin{aligned}
& \text { سياسگَزارى } \\
& \text { نغارندكان بر خود لازم مى سانند از جناب دكتر سيدمنصور } \\
& \text { سيدسـجادى (سريرسـت هيئـت باسـتان شناسـى شـهر }
\end{aligned}
$$

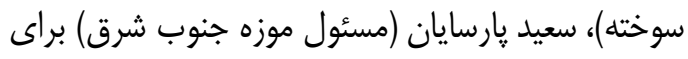

South Region of Sistan,Iran. Mediterranean Archaeology and Archaeometry. Vol 5. NO 3.pp. 45-56.

Salvatori, S \& M. Tosi., 2005, Shahr-i Sokhta Revised Sequence. In C. Jarrige and V. Lefevre, (eds.) South Asian Archaeology 2001: 281-292, Editions Recherches sur les Civilisations, Paris.

Salvatori, S. and M. Vidale,. (1997). Sokhta 19751978: Central Quarters Excavations, preliminary report. Roma: Instituto italiano per l'Africa e l'Oriente, IsLAO.

Salvatori, S., \& Tosi, M. (2001). Shahr-i Sokhta revised sequence. South Asian Archaeology, 1, 281-292.

Sarianidi, V. I. (1983). The Pottery of Shahr-i Sokhta I and its Southern Turkmenian Connections. Prehistoric Sistan I, In: Tosi, M. (ed.), Prehistoric Sistan 1, IsMEO, Rome 183-198.

Tosi, M. (1984). The notion of craft specialization and its representation in the archaeological record of early states in the Turanian Basin. Marxist perspectives in archaeology, 22-52.

Tosi, M. (Ed.). (1983). Prehistoric Sistan. IsMEO.

Tosi, M., (1973), The cultural Sequence of Shahr I Sokhta. Bull. Asia Instit. Pahlavi Univ., 3: 64-80.

Vidale, M., \& Tosi, M. (1996). The development of wheel throwing at Shahr-i Sokhta slow and fast revolutions towards statehood. East and West, 46(3-4):, 251-269.

Wong, E. H., Petrie, C. A., \& Fazeli, H. (2010). Cheshmeh Ali Ware: A Petrographic and Geochemical Study of A Transitional Chalcolithic Period Ceramic Industry on The Northern Central Plateau of Iran. Iran, 47: 11-26. 